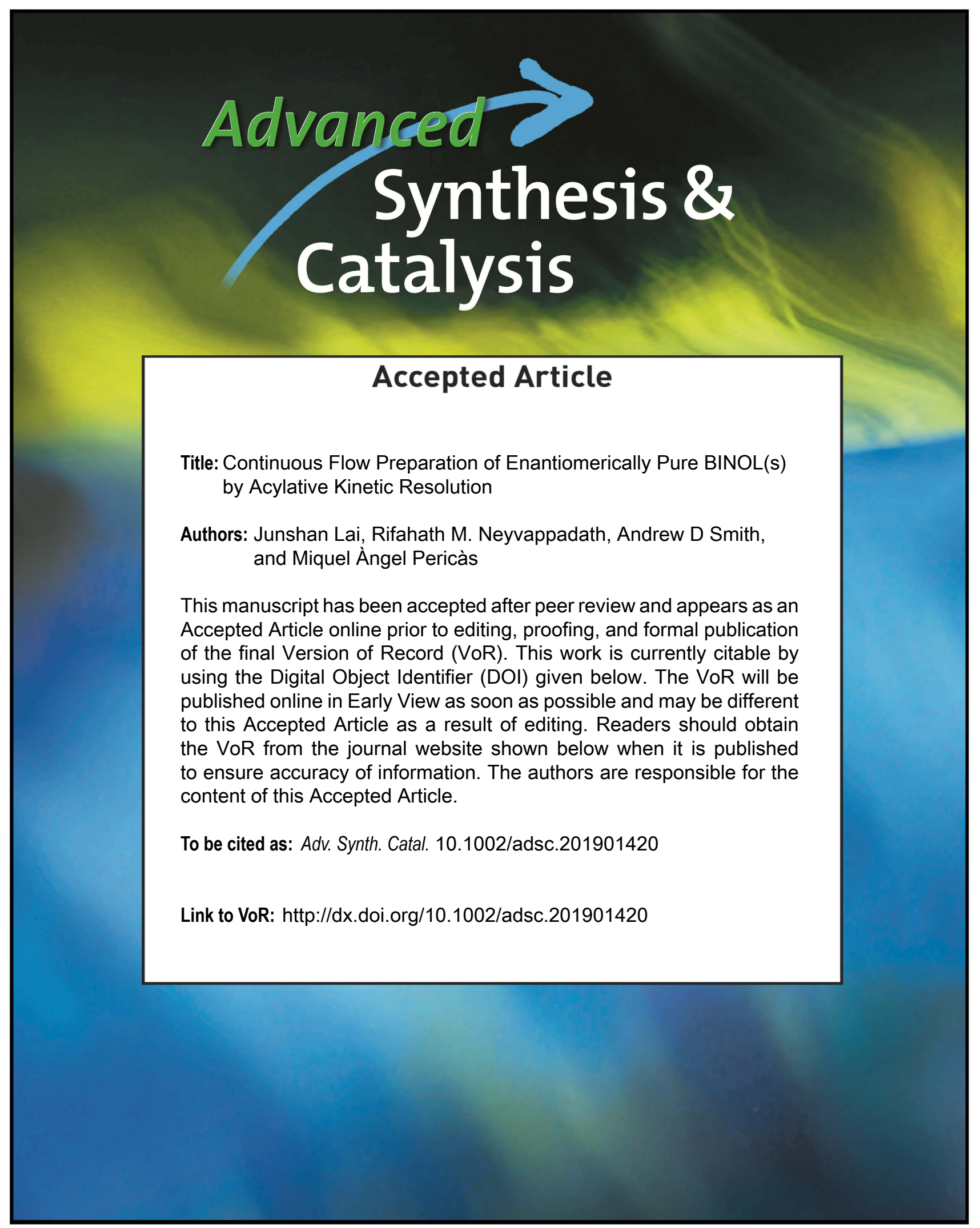


DOI: 10.1002/adsc.201((will be filled in by the editorial staff))

\title{
Continuous Flow Preparation of Enantiomerically Pure BINOL(s) by Acylative Kinetic Resolution
}

\author{
Junshan Lai, ${ }^{\text {a,b }}$ Rifahath M. Neyyappadath, ${ }^{\mathrm{c}}$ Andrew D. Smith, ${ }^{\mathrm{c}}$ and Miquel A. \\ Pericàs ${ }^{\mathrm{a}, \mathrm{d}, *}$ \\ a Institute of Chemical Research of Catalonia (ICIQ), The Barcelona Institute of Science and Technology, Av. Països \\ Catalans, 16, 43007 Tarragona, Spain. mapericas@iciq.es. \\ b Departament de Química Analítica i Química Orgànica, Universitat Rovira i Virgili, 43007 Tarragona, Spain \\ ${ }^{c}$ EaStCHEM, School of Chemistry, University of St Andrews, North Haugh, St Andrews, KY16 9ST, U.K. \\ ${ }^{\mathrm{d}}$ Departament de Química Inorgànica i Orgànica, Universitat de Barcelona (UB), 08028 Barcelona, Spain.
}

Received: ((will be filled in by the editorial staff))

Supporting information for this article is available on the WWW under http://dx.doi.org/10.1002/adsc.201\#\#\#\#\#.((Please delete if not appropriate))

\begin{abstract}
A polystyrene-immobilized isothiourea has been applied to the enantioselective acylative kinetic resolution $(\mathrm{KR})$ of monoacylated BINOL(s) with inexpensive isobutyric anhydride in batch and flow. High selectivity values $(s=29$ at $0{ }^{\circ} \mathrm{C}$ ) and a remarkable stability of the catalytic system in the operation conditions have been recorded for unsubstituted BINOL. No significant loss of activity/selectivity is recorded after 10 consecutive KR cycles in batch. A continuous flow process has been implemented and operated with a $100 \mathrm{mmol}(32.8 \mathrm{~g})$ sample of racemic monoacetylated BINOL in dichloromethane solution in an 84 hours experiment with a packed bed reactor containing $1 \mathrm{~g}\left(f=0.37 \mathrm{mmol} . \mathrm{g}^{-1}\right)$ of the functional resin $(s=17-21)$. Residence time can be decreased to $10 \mathrm{~min}$ with the same reactor to achieve a conversion of $58 \%$ with a selectivity factor $s=17$ when a more highly functionalized catalyst $\left(f=0.88 \mathrm{mmol}^{-1}\right)$ is used. This translates into a remarkable combined productivity of $5.5 \mathrm{mmol}_{\mathrm{prod}} \cdot \mathrm{mmol}_{\mathrm{cat}}{ }^{-1} \cdot \mathrm{h}^{-1}$.
\end{abstract}

Keywords: BINOL; Kinetic resolution; Isothiourea organocatalysts; Immobilization; Continuous flow

\section{Introduction}

Enantiopure 1,1'-binaphthols (BINOLs) are probably the most versatile building blocks for the preparation of chiral catalysts. Their almost unlimited applicability covers the broad areas of metal catalysis and organocatalysis, and simple structural variations lead to applications in the comprehensive area of Brønsted/Lewis acid/base catalysis. ${ }^{[1]}$ Although the development of methods for the asymmetric oxidative dimerization of naphthyl derivatives has experienced significant progress in recent years, ${ }^{[2]}$ the kinetic resolution (KR) of racemic biaryl derivatives (and, in particular, of unsubstituted BINOL) continues to be the main entrance to the ever growing family of 1,1'binaphthols and derivatives ${ }^{[1,3]}$ Within this approach, the acylative KR of 1,1'-binaphthyl derivatives has received comparatively low attention in spite of its potential. ${ }^{[4]}$ In 2014, Sibi reported chiral 4dimethylaminopyridine catalysts achieving selectivity factors of up 51 in the considered acylative process (Scheme 1a). ${ }^{[5]}$ In the same year, Zhao (Scheme 1b) reported the highly efficient NHC-catalyzed acylative KR of a wide range of 1,1'-biaryl-2,2'-diols and amino alcohols leading to products with consistently very high enantiomeric purity $\left(99 \%\right.$ ee). ${ }^{[6]}$ In spite of its performance, these methods involve reaction conditions, such as low operation temperature ${ }^{[5]}$ or long reaction time, ${ }^{[6]}$ that render them impractical for large scale operation.

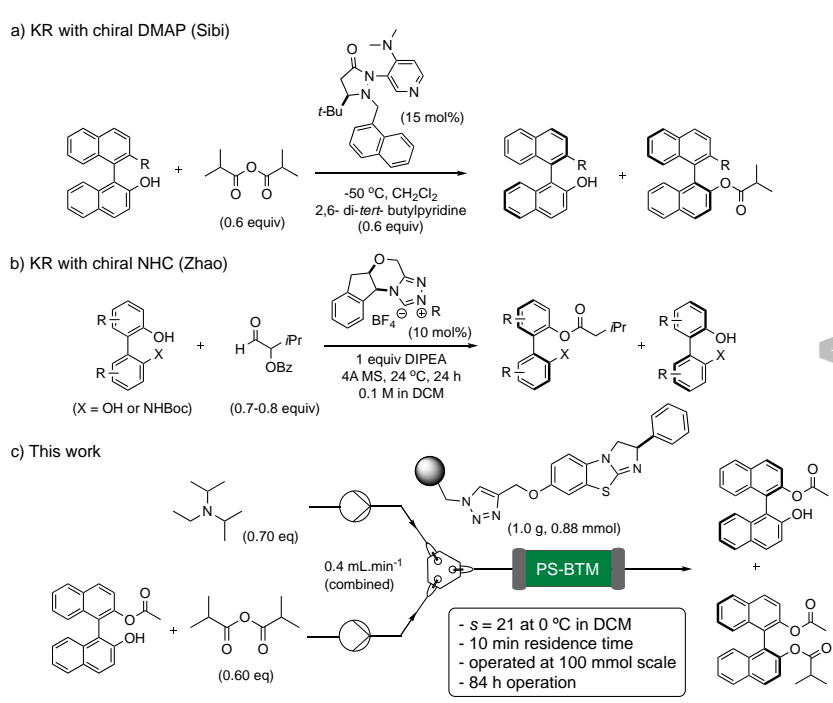

Scheme 1. Approaches to the acylative KR of BINOL and related compounds. 
With these limitations in mind, and taking into account the industrial importance of enantiopure BINOLs and their derivatives, we considered alternative processes that could operate under mild reaction conditions with high turnover frequencies, with the ultimate goal of developing a continuous flow process for the preparation of enantiomerically pure BINOL (Scheme 1c). ${ }^{[7]}$

Chiral isothioureas, first reported by Birman in 2006, ${ }^{[8]}$ have become useful catalysts for the acylative KR of alcohols ${ }^{[9]}$ and carboxylic acids ${ }^{[10]}$ and, quite recently, for the desymmetrization of axially chiral diols..$^{[1]}$ Benzotetramisole (BTM), the archetypical example of chiral isothioureas, is among the most readily available and effective nonenzymatic enantioselective acylation catalysts $^{[12]}$ reported to date. ${ }^{[8,13]}$ In 2016, we reported the preparation of a polystyrene-supported BTM analogue which was successfully used in the domino Michael addition/cyclization reaction with excellent yields and very high enantioselectivities, ${ }^{[14]}$ and later applied to asymmetric [4+2] and [8+2] annulation reactions. ${ }^{[15]}$ More recently, in a joint effort of our laboratories, new polystyrene-supported isothiourea catalysts, based on the homogeneous catalysts BTM and HyperBTM, have been prepared and used for the acylative KR of secondary ${ }^{[16 a]}$ and secondary and tertiary heterocyclic alcohols ${ }^{[16 b]}$ in batch and in continuous flow. However, there are currently no examples where BTM catalysts have been applied for the acylative KR of 1,1'-bi-2-naphthol (BINOL). We report herein the application of second generation immobilized BTM in the acylative KR of BINOLs with high selectivity in batch and continuous flow, and we show that the flow procedure can be operated at the $100 \mathrm{mmol}$ scale $(32.8 \mathrm{~g})$ without any decrease in the performance of the catalyst.

\section{Results and Discussion}

We decided to evaluate isothioureas 5a-d as catalysts for this study. The selection includes monomers 5b-c as well as the first and second generation PS-immobilized BTM-type catalysts $\mathbf{5 a}^{[14]}$ and $5 \mathbf{d},{ }^{[16 b]}$ and is guided by previous results in the KR of axially chiral diols with homogeneous isothioureas (Figure 1). ${ }^{[1]}$

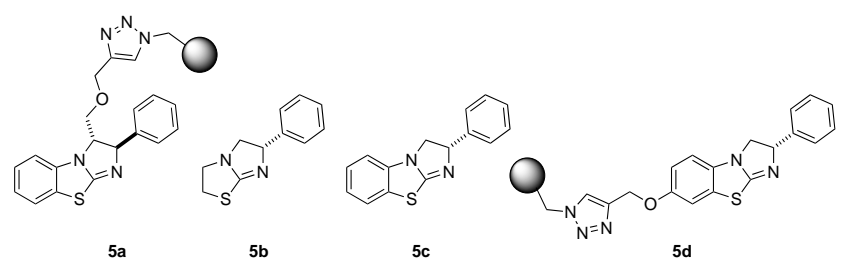

Figure 1. Catalysts used in this study.

For the preparation of $\mathbf{5 d}$ (Scheme 2) we used a slight modification of the reported procedure that simplifies the installment of the propargyl anchor by performing the replacement of the methoxy by a propargyloxy group at the beginning of the sequence. Thus, 2-chloro-6-methoxybenzothiazole (1) was demethylated with $\mathrm{BBr}_{3}$ and alkylated without isolation with propargyl bromide (2) to afford 2chloro-6-propynyloxybenzo[d]thiazole (3) in 93\% yield. Then, following a modification of a literature procedure, ${ }^{[17]}$ neat 3 was heated in a pressure tube (135 ${ }^{\circ} \mathrm{C}, 24 \mathrm{~h}$ ) with a stoichiometric amount of $(S)$-2-amino2-phenylethanol and Hunig's base (2 eq.) followed by in situ cyclization to afford 8-propynyloxy-BTM (4) in $58 \%$ yield (3 steps). Immobilization of $\mathbf{4}$ onto azidomethyl polystyrene, prepared from commercial Merrifield resin, was achieved by a $\mathrm{Cu}$-catalyzed azide-alkyne cycloaddition reaction. The nitrogen content of the resulting polymer, determined by elemental analysis, was used to calculate the functionalization ${ }^{[18]}$ of $\mathbf{5 d}\left(0.37 \mathrm{mmol} \mathrm{g}^{-1}\right)$, and this value was used to determine the catalyst loading in all subsequent KRs.

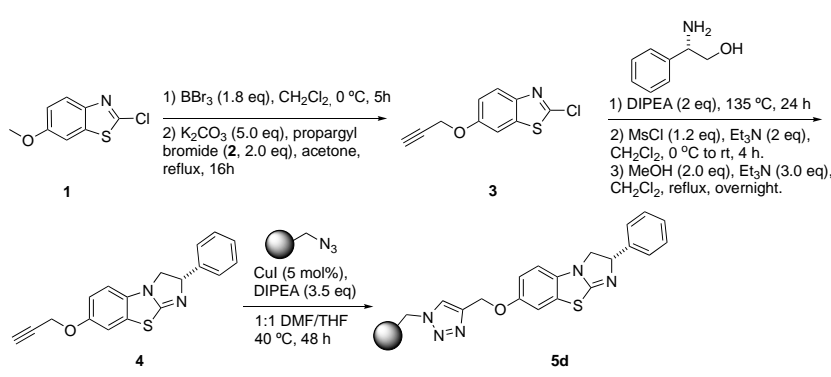

Scheme 2. Synthesis of the second-generation polystyrenesupported BTM catalyst (5d).

Our initial studies focused on the KR of parent BINOL 6a with anhydrides, using $5 \mathrm{~mol} \%$ of BTM 5c as the catalyst (Scheme 3). Unfortunately, the reactions were poorly selective, mixtures of binol with its monoacylated and bisacylated products being always obtained. Moreover, the reproducibility of these experiments was rather poor.


Scheme 3. Acylative KR of $r a c$-BINOL (6a).

In light of these results, we modified our strategy to the acylative KR of monoacylated BINOLs (Table 1). We first used isobutyric anhydride as an acyl donor ( 0.6 equiv) for the KR of a series of monoacylated BINOLs in $\mathrm{CH}_{2} \mathrm{Cl}_{2}$ at room temperature. As shown in entry 1, the KR of monoacetyl BINOL with isobutyric anhydride took place with a selectivity factor $s=14$ at $58 \%$ conversion. The use of larger acyl groups on the monoacylated BINOL substrate, such as isobutyryl, pivaloyl or benzoyl, gave much lower selectivities 
(entries 2-4). According to this, monoacetyl BINOL 8a was used as the model substrate to optimise the nature of the acylating agent 7 . As shown in entry 6 , pivalic anhydride did not work in this reaction, while both acetic anhydride and benzoic anhydride (entries 5 and 7) gave low selectivities. Accordingly, the combination of 8a and isobutyric anhydride was established as optimal for the planned KR process.

Table 1. Acylative KR of monoacylated BINOLs. ${ }^{\text {a) }}$

\begin{tabular}{|c|c|c|c|c|c|c|c|c|}
\hline \multicolumn{3}{|c|}{ rac-8x } & \multicolumn{2}{|c|}{$7 y(0.6$ eq) } & \multicolumn{2}{|c|}{$8 x$} & $9 \mathrm{x}$ & \\
\hline & 8 & $\mathrm{R}^{1}$ & 9 & $\mathrm{R}^{2}$ & $\begin{array}{c}8 \mathrm{ee}^{\mathrm{b})} \\
{[\%]}\end{array}$ & $\begin{array}{c}9 \mathrm{ee}^{\mathrm{b})} \\
{[\%]}\end{array}$ & $\begin{array}{l}\mathrm{c}^{\mathrm{c})} \\
{[\%]}\end{array}$ & $s^{\mathrm{d})}$ \\
\hline 1 & $8 \mathbf{a}$ & $\mathrm{Me}$ & 9ab & ${ }^{i} \operatorname{Pr}$ & 91 & 65 & 58 & 14 \\
\hline 2 & $8 b$ & ${ }^{i} \mathrm{Pr}$ & $9 \mathrm{bb}$ & ${ }^{i} \mathrm{Pr}$ & 52 & 42 & 55 & 4 \\
\hline 3 & $8 c$ & ${ }^{t} \mathrm{Bu}$ & $9 \mathrm{cb}$ & ${ }^{i} \mathrm{Pr}$ & 43 & 33 & 56 & 3 \\
\hline 4 & 8d & $\mathrm{Ph}$ & $9 \mathrm{db}$ & ${ }^{i} \operatorname{Pr}$ & 78 & 51 & 60 & 7 \\
\hline 5 & $8 \mathbf{a}$ & $\mathrm{Me}$ & 9aa & $\mathrm{Me}$ & 24 & 18 & 57 & 2 \\
\hline 6 & 8a & $\mathrm{Me}$ & 9ac & ${ }^{t} \mathrm{Bu}$ & - & - & - & - \\
\hline 7 & $8 \mathbf{a}$ & $\mathrm{Me}$ & 9ad & $\mathrm{Ph}$ & 34 & 31 & 52 & 3 \\
\hline
\end{tabular}

a) Reaction conditions: (+/-) 8 (0.5 mmol, 1 eq.), 7y (0.3 mmol, 0.6 eq.) and $i \operatorname{Pr}_{2} \mathrm{NEt}(45.2 \mathrm{mg}, 61 \mu \mathrm{L}, 0.35 \mathrm{mmol}, 0.7$ eq.), catalyst $(0.025 \mathrm{mmol}), \mathrm{CH}_{2} \mathrm{Cl}_{2}(2.5 \mathrm{~mL})$, rt. b) ee determined by HPLC. ${ }^{c)}$ Conversion determined by Kagan's equations. ${ }^{\text {d) }}$ Selectivity factors calculated from ee data.

Since the main goal of this project was applying immobilized isothiourea catalysts to the KR process, 5d featuring an almost unperturbed BTM structure was directly used to optimise the reaction solvent (Table 2). Gratifyingly, the reaction rate was not affected by the heterogeneous nature of the catalyst (in both cases the process was complete in $10 \mathrm{~h}$ ) and the $s$ value even increased $(s=18)$ when chloroform was used at room temperature (entry 1$)$. Slightly lower selectivity $(s=$ 14) was recorded in dichloromethane under the same conditions (entry 4), while non-chlorinated solvents like DMF, $\mathrm{CH}_{3} \mathrm{CN}$, Dioxane, $\mathrm{Et}_{2} \mathrm{O}$, toluene and THF provided only moderate selectivities (entries 7-11). With halogenated solvents, the effect of temperature was also studied. Working in chloroform, a temperature decreased to $0{ }^{\circ} \mathrm{C}$ led to an increased $\mathrm{s}$ value of 29 (Table 2, entry 2) without any significant decrease in catalytic activity. However, when the reaction temperature was increased to $60{ }^{\circ} \mathrm{C}(4 \mathrm{~h}$ reaction time), the s value decreased to 6 . According to these results, we decided to use $\mathrm{CHCl}_{3}$ and $\mathrm{CH}_{2} \mathrm{Cl}_{2}$ as solvents in the acylative KR performed in batch, and $\mathrm{CH}_{2} \mathrm{Cl}_{2}$ for the processes in continuous flow.
Table 2. Solvent optimization for the acylative KR. ${ }^{\text {a) }}$

\begin{tabular}{|c|c|c|c|c|c|}
\hline \multirow{2}{*}{$\mathrm{rac}$} & \multicolumn{2}{|c|}{$7 \mathrm{~b}(0.6 \mathrm{eq})$} & \multirow[b]{2}{*}{$\begin{array}{l}9 \mathbf{a b} \\
\mathrm{ee}^{\mathrm{b})} \\
{[\%]}\end{array}$} & \multicolumn{2}{|c|}{ 9ab } \\
\hline & solvent & $\begin{array}{c}\mathbf{8} \mathbf{a ~ e e}^{\mathrm{b})} \\
{[\%]}\end{array}$ & & $\begin{array}{c}\mathrm{c}^{\mathrm{c})} \\
{[\%]}\end{array}$ & $s^{\mathrm{d})}$ \\
\hline 1 & $\mathrm{CHCl}_{3}$ & 95 & 67 & 58 & 18 \\
\hline 2 & $\mathrm{CHCl}_{3}\left(\mathrm{O}^{\circ} \mathrm{C}\right)$ & 95 & 78 & 55 & 29 \\
\hline 3 & $\mathrm{CHCl}_{3}\left(60^{\circ} \mathrm{C}\right)$ & 70 & 47 & 60 & 6 \\
\hline 4 & $\mathrm{CH}_{2} \mathrm{Cl}_{2}$ & 90 & 65 & 58 & 14 \\
\hline 5 & $\mathrm{CH}_{2} \mathrm{Cl}_{2}\left(\mathrm{O}^{\circ} \mathrm{C}\right)$ & 92 & 74 & 55 & 21 \\
\hline 6 & $\mathrm{CH}_{3} \mathrm{CN}$ & 26 & 21 & 55 & 2 \\
\hline 7 & DMF & 28 & 23 & 55 & 2 \\
\hline 8 & toluene & 83 & 61 & 58 & 10 \\
\hline 9 & THF & 89 & 61 & 59 & 12 \\
\hline 10 & dioxane & 83 & 58 & 59 & 9 \\
\hline 11 & $\mathrm{Et}_{2} \mathrm{O}$ & 77 & 55 & 58 & 8 \\
\hline
\end{tabular}

a) Reaction conditions: $\mathrm{rac}-\mathbf{8 a}$ ( $164 \mathrm{mg}, 0.5 \mathrm{mmol}, 1 \mathrm{eq}$.), $7 \mathbf{b}$ (47.4 mg, $50 \mu \mathrm{L}, 0.3 \mathrm{mmol}, 0.6$ eq.) and $\mathrm{iPr}_{2} \mathrm{NEt}(45.2 \mathrm{mg}$, $61 \mu \mathrm{L}, 0.35 \mathrm{mmol}, 0.7$ eq.), $5 \mathbf{d}(135 \mathrm{mg}, 5 \mathrm{~mol} \%, \mathrm{f}=0.37$ mmol\%), solvent $(2.5 \mathrm{~mL})$, rt or indicated temperature. ${ }^{\text {b) }}$ ee determined by HPLC. ${ }^{c)}$ Conversion determined by Kagan's equations. ${ }^{\text {d) }}$ Selectivity factors calculated from ee data.

As a final step in the optimization process, we wanted to compare the first- and second-generation polystyrene-supported BTM analogues (5a and 5d) in the acylative KR (Table 3) in the optimal solvent. Results with the homogeneous catalysts $\mathbf{5 b}$ and $\mathbf{5 c}$ have been included for comparison purposes. The comparison gave a clear result in favour of $\mathbf{5 d}$. Thus, as shown in entry 1 , 5a proved unsuitable for this transformation, affording enantioenriched 8a and 9ab with very poor selectivity ( $s=3$ ). It is thus strongly suggested that the presence of the linker in position 3 of the heterocyclic nucleus leads to a much less efficient chemzyme for this particular process. To gain some further indication on the structural factors of $\mathbf{5}$ affecting selectivity, the reaction was also tested with $\mathbf{5 b}$ and 5c. With tetramisole $\mathbf{5 b}$ (entry 2) the reaction was poorly selective, but benzotetramisole $\mathbf{5 c}$ afforde. the best selectivity results over a temperature range ranging from room temperature to $-20{ }^{\circ} \mathrm{C}$, where a selectivity of 36 was reached (entries 3-5). A similar decrease in temperature working with 5d (entry 8) proved deleterious for catalytic activity and selectivity, and this can be attributed to the arrest of mobility of the polymer at this temperature, preventing swelling and the achievement of an optimal conformation. From a structural perspective it can be concluded that the presence of a condensed benzo ring in positions 2,3 of tetramisole is necessary for high selectivity in the acylative KR. Furthermore, a bulky substituent (the 
polymer chain) in one of the distal positions on the benzo group is well tolerated in terms of both catalytic activity and enantioselectivity.

Table 3. Comparison of catalysts 5a-d in the acylative KR of $8 \mathbf{a}$ with $7 \mathbf{b} .^{\text {a) }}$

\begin{tabular}{|c|c|c|c|c|c|c|}
\hline & $a c-8 \mathbf{a}$ & b ( 0.6 eq) & & 3a & & \\
\hline & Cat. & $\begin{array}{c}\mathrm{t} \\
{[\mathrm{h}]}\end{array}$ & $\begin{array}{c}\mathbf{8 a} e^{\mathrm{b})} \\
{[\%]}\end{array}$ & $\begin{array}{c}\text { 9ab ee }{ }^{b)} \\
{[\%]}\end{array}$ & $\begin{array}{c}\mathrm{c}^{\mathrm{c})} \\
{[\%]}\end{array}$ & $S^{d)}$ \\
\hline 1 & $5 a$ & 8 & -41 & -33 & 57 & 3 \\
\hline 2 & $5 b$ & 8 & 42 & 30 & 58 & 3 \\
\hline 3 & $5 c$ & 8 & 98 & 73 & 57 & 28 \\
\hline 4 & $5 \mathbf{c}\left(0^{\circ} \mathrm{C}\right)$ & 8 & 99 & 71 & 58 & 30 \\
\hline 5 & 5c $\left(-20^{\circ} \mathrm{C}\right)$ & 16 & 98 & 78 & 56 & 36 \\
\hline 6 & $5 d$ & 10 & 95 & 67 & 59 & 18 \\
\hline 7 & $5 \mathbf{d}\left(0^{\circ} \mathrm{C}\right)$ & 12 & 95 & 78 & 55 & 29 \\
\hline 8 & $\mathbf{5 d}\left(-20^{\circ} \mathrm{C}\right)$ & 24 & 33 & 61 & 35 & 6 \\
\hline
\end{tabular}

a) Reaction conditions: $\mathrm{rac}-\mathbf{8 a}$ (164 mg, $0.5 \mathrm{mmol}, 1$ eq.), 7b (47.4 mg, $50 \mu \mathrm{L}, 0.3 \mathrm{mmol}, 0.6$ eq.), $i \operatorname{Pr}_{2} \mathrm{NEt}$ (45.2 mg, 61 $\mu \mathrm{L}, 0.35 \mathrm{mmol}, 0.7$ eq.), 5a-d (0.025 mmol), $\mathrm{CHCl}_{3}(2.5$ $\mathrm{mL})$, rt or indicated temperature. ${ }^{\mathrm{b})}$ ee determined by HPLC.

c) Conversion determined by Kagan's equations. d) Selectivity factors calculated from ee data.

Although our main goal in this project was the development of a practical procedure for the preparation of enantiopure BINOL, we decided to investigate the scope of the catalytic acylative KR reaction in batch using the immobilized BTM catalyst 5d in $\mathrm{CHCl}_{3}$ (Table 4) at $0{ }^{\circ} \mathrm{C}$. Catalyst $\mathbf{5 d}$ does not behave as a promiscuous chemzyme being rather specific with respect to the nature and substitution of the substrate. Substituents on the distal ring are generally well tolerated $(\mathbf{8 e}, \mathbf{8 h}, \mathbf{8 i})$, but excessive steric congestion (8f) leads to a significant decrease in enantioselectivity. Acylation of one of the oxygen atoms in the BINOL system $(\mathbf{8 g})$ and the presence of the two connected naphthyl units $(\mathbf{8 g}, \mathbf{8 1}, \mathbf{8 m})$ seem to be strict structural requirements, as the absence of substitution in $o-, o^{\prime}-$ in the BINOL system $(\mathbf{8 j}, \mathbf{8 k}$, $\mathbf{8 m})$ also seems to be. Fortunately, the parent substrate of interest 8a, stands as the optimal substrate for the acylative KR, achieving a selectivity of up to 29 with the immobilized catalyst 5d and up to 36 with the homogeneous BTM 5c. It is worth noting that either scalemic 8a or the diester 9 ab can be easily converted into the enantiomeric forms of BINOL through saponification and recrystallization from either toluene or chloroform (ESI).
Table 4. Scope of the acylative KR of BINOLs catalyzed by $5 d$. ${ }^{a}$

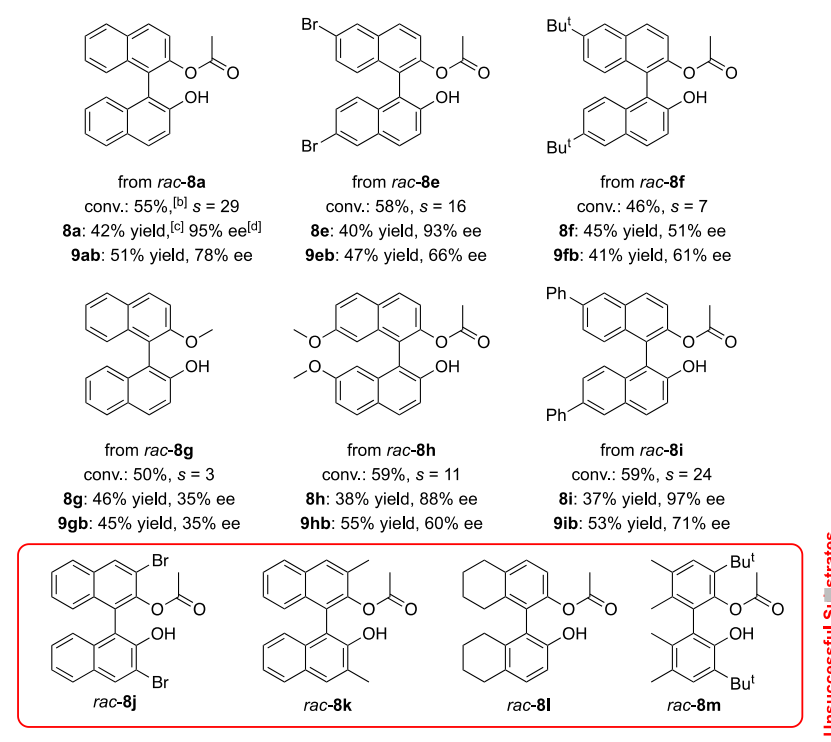

a) Reaction conditions: $\mathrm{rac}-\mathbf{8}$ (0.5 mmol, 1 eq.), $7 \mathbf{b}$ (47.4 mg, $50 \mu \mathrm{L}, 0.3 \mathrm{mmol}, 0.6$ eq.), $i \operatorname{Pr}_{2} \mathrm{NEt}(45.2 \mathrm{mg}, 61 \mu \mathrm{L}, 0.35$ mmol, 0.7 eq.), $5 d$ (135 mg, $5 \mathrm{~mol} \%), \mathrm{CHCl}_{3}(2.5 \mathrm{~mL}), 0{ }^{\circ} \mathrm{C}$, 10 h. b) Conversion determined by Kagan's equations. c) Isolated yield. d) ee determined by HPLC.

In view of the excellent results achieved with catalyst $\mathbf{5 d}$ in the acylative KR of $\mathbf{8 a}$, the study of th recyclability of the catalyst in this particular process was undertaken. The process was initially studied ir chloroform, however, slow deactivation of the catalyst was observed although selectivity remained constant over ten consecutive cycles (see Table S1). The deactivation process can be tentatively attributed to hydrolysis of the intermediate acylisothiouronium species as suggested by Birman, ${ }^{[17 a]}$ and we reasoned that using the less labile and less toxic anhydrous $\mathrm{CH}_{2} \mathrm{Cl}_{2}$ could minimize the deactivation problem without requiring solvent pre-treatments. As shown in Table 5 , no decrease in catalytic activity or enantioselectivity was observed in a ten-cycle experiment in this solvent. 
Table 5. Recycling of $\mathbf{5 d}$ in the acylative KR of $\mathrm{rac}-\mathbf{8 a}$ with 7b in $\mathrm{CH}_{2} \mathrm{Cl}_{2}$.

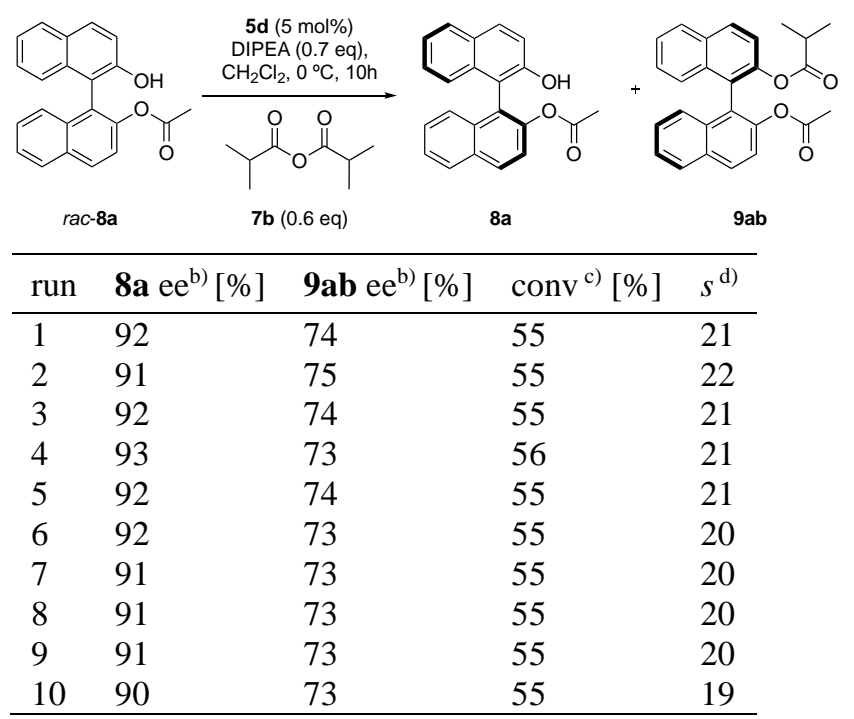

a) Reaction conditions: $\mathrm{rac}-\mathbf{8 a}$ (164 mg, $0.5 \mathrm{mmol}, 1 \mathrm{eq}.), 7 \mathbf{a}$ (50 uL, $0.3 \mathrm{mmol}, 0.6$ eq.) $i \operatorname{Pr}_{2} \mathrm{NEt}(61 \mathrm{uL}, 0.35 \mathrm{mmol}, 0.7$ eq), PS-cat. 5d (135 mg, $5 \mathrm{~mol} \%), \mathrm{CH}_{2} \mathrm{Cl}_{2}(2.5 \mathrm{~mL}), 0{ }^{\circ} \mathrm{C}$, 10 h. ${ }^{\text {b) }}$ ee determined by HPLC. ${ }^{\text {c) }}$ Conversion determined by Kagan's equations. ${ }^{\text {d) }}$ Selectivity factors calculated from ee data.

Once the robustness of $\mathbf{5 d}$ in dichloromethane had been established, a large scale $(100 \mathrm{mmol})$ experiment in continuous flow was planned. The employed setup is shown in Figure 3. Catalyst $5 \mathbf{d}(1.0 \mathrm{~g}, 0.37 \mathrm{mmol})$ was swollen in $\mathrm{CH}_{2} \mathrm{Cl}_{2}$ in a size-adjustable medium pressure glass column to create a packed bed reactor, and a cooling jacket was attached to maintain an internal temperature of $0^{\circ} \mathrm{C}$. Two syringes mounted on a single syringe pump were used to feed the reagents to the flow reactor. One of the syringes contained a solution of $\mathbf{8 a}$ and isobutyric anhydride (7b) in dichloromethane, and the second one a solution of $i \mathrm{Pr}_{2} \mathrm{NEt}$ in dichloromethane, with concentrations adapted to secure the desired ratio $(0.2 \mathrm{M}$ in $\mathbf{8 a}$ in the combined flow). The optimal combined flow rate was initially determined as $0.1 \mathrm{~mL} \cdot \mathrm{min}^{-1}$ at a reaction temperature of $0^{\circ} \mathrm{C}$. Then, the preparative experiment was performed under the optimal condition from 250 $\mathrm{mL}$ of a $0.4 \mathrm{M}$ solution of $\mathrm{rac}-\mathbf{8 a}(32.8 \mathrm{~g}, 100 \mathrm{mmol})$ in $\mathrm{CH}_{2} \mathrm{Cl}_{2}$. The experiment took $84 \mathrm{~h}$ to completion, and the measured residence time of the employed setup (visual inspection with a solution of methyl red) was $c a .40$ min. Data at different operation times have been summarized in Table 6 .
Table 6. Continuous flow acylative KR of $8 \mathbf{a}$ with isobutyric anhydride (7b) catalyzed by $\mathbf{5 d}(f=0.37 \mathrm{mmol.g}$ $\left.{ }^{1}\right) .{ }^{\text {a) }}$

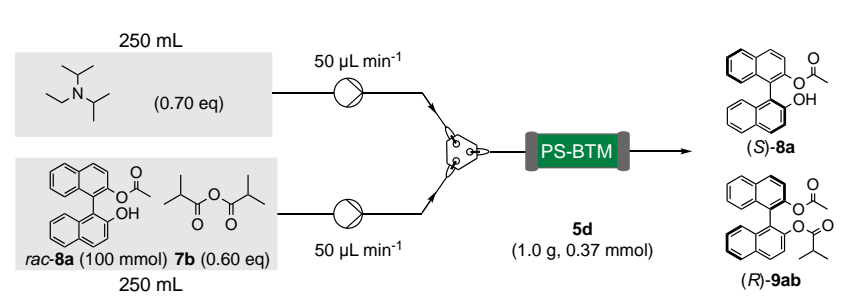

\begin{tabular}{lllllll}
\hline $\begin{array}{l}\text { Operation } \\
\text { time }[\mathrm{h}]\end{array}$ & $\begin{array}{l}\mathbf{8 a} \\
\mathrm{ee}^{\mathrm{b})} \\
{[\%]}\end{array}$ & $\begin{array}{l}\mathbf{8 a} \\
\text { yield }^{\mathrm{c})} \\
{[\%]}\end{array}$ & $\begin{array}{l}\mathbf{9 a b} \\
\mathrm{e} \mathrm{e}^{\mathrm{b})} \\
{[\%]}\end{array}$ & $\begin{array}{l}\mathbf{9 a b} \\
\text { yield }^{\mathrm{c})} \\
{[\%]}\end{array}$ & $\begin{array}{l}\text { Conv }^{\mathrm{d})} \\
{[\%]}\end{array}$ & $\begin{array}{l}s \\
\mathrm{e})\end{array}$ \\
\hline 0 & 94 & 40 & 62 & 57 & 60 & 14 \\
2 & 91 & 43 & 69 & 50 & 57 & 17 \\
12 & 96 & 40 & 64 & 58 & 60 & 17 \\
21 & 96 & 40 & 64 & 55 & 60 & 17 \\
32 & 96 & 41 & 66 & 56 & 59 & 18 \\
42 & 96 & 43 & 67 & 52 & 59 & 19 \\
56 & 97 & 39 & 66 & 55 & 60 & 20 \\
66 & 96 & 43 & 69 & 55 & 58 & 21 \\
76 & 96 & 42 & 69 & 50 & 58 & 21 \\
84 & 90 & 45 & 74 & 49 & 55 & 20 \\
\hline
\end{tabular}

a) Reaction conditions: $\mathrm{rac}-\mathbf{8 a}$ ( 1 eq., $0.2 \mathrm{M}$ in $\mathrm{CH}_{2} \mathrm{Cl}_{2}$ ), $7 \mathbf{b}$ (0.6 eq., $0.2 \mathrm{M}$ in $\mathrm{CH}_{2} \mathrm{Cl}_{2}$ ), $i \mathrm{Pr}_{2} \mathrm{NEt}(0.7$ eq., $0.2 \mathrm{M}$ in $\left.\mathrm{CH}_{2} \mathrm{Cl}_{2}\right)$, 5d $(1.0 \mathrm{~g}), 0{ }^{\circ} \mathrm{C}, 0.1 \mathrm{~mL} \cdot \mathrm{min}^{-1}$ combined flow, residence time $40 \mathrm{~min} .{ }^{\text {b) }}$ ee determined by HPLC. ${ }^{\mathrm{c})}$ Isolated yield d) Conversion determined by Kagan's equations. Selectivity factors calculated from ee data.

It was highly rewarding to see that $\mathbf{5} \mathbf{d}$ does not show any sign of deterioration after 84 hours operation. This was clearly an indication of potential practical applicability in the continuous preparation of both enantiomers of BINOL. Taking into account that the original preparation of ent-5d $\mathbf{d}^{[16 \mathrm{a}]}$ provided a more highly functionalized resin $\left(f=0.88 \mathrm{mmol} . \mathrm{g}^{-1}\right)$, we reasoned that the use of this particular resin could lead to an important increase in the productivity of the acylative KR. To test this possibility a new packed bed reactor was prepared with $1.0 \mathrm{~g}$ of ent $\mathbf{5 d}$ with $f=0.88$ mmol.g ${ }^{-1}$. Working with this resin under the same experimental conditions of the previous flow process, we could easily determine that a combined flow rate of $0.4 \mathrm{~mL} . \mathrm{min}^{-1}$ provided a conversion of $c a .58 \%$ (Table 7). At this rate, the acylative KR of a sample of 12.6 o (38.4 mmol) of rac-8a could be completed in a 8 hours experiment. This represents an impressive four-fold increase in productivity relative to the use of $\mathbf{5 d}$ with $f$ $=0.37 \mathrm{mmol} . \mathrm{g}^{-1}$, resulting in residence times of $c a .10$ min. Interestingly, no variation in selectivity or catalytic activity could be detected during the whole experiment. 
Table 7. Continuous flow acylative KR of $\mathbf{8 a}$ with isobutyric anhydride (7b) catalyzed by ent-5d $(f=0.88$ mmol.g-1 ${ }^{\text {a) }}$
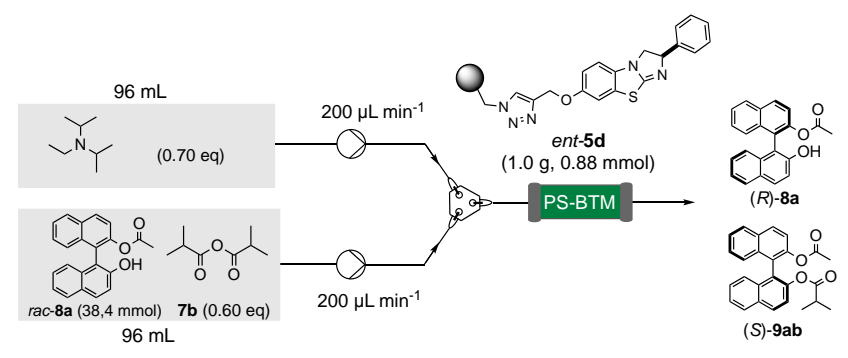

\begin{tabular}{|c|c|c|c|c|}
\hline $\begin{array}{l}\text { Operation } \\
\text { time }[\mathrm{h}]\end{array}$ & $\begin{array}{ll}\mathbf{8 a} & \mathrm{ee}^{\mathrm{b})} \\
{[\%]} & \end{array}$ & $\begin{array}{ll}\mathbf{9 a b} & \mathrm{ee}^{\mathrm{b})} \\
{[\%]} & \end{array}$ & $\operatorname{conv}^{\mathrm{c})}[\%]$ & $s^{\mathrm{d})}$ \\
\hline 0.5 & -90 & -66 & 58 & 14 \\
\hline 1 & -92 & -67 & 58 & 16 \\
\hline 2 & -93 & -68 & 58 & 17 \\
\hline 3 & -93 & -68 & 58 & 17 \\
\hline 4 & -93 & -68 & 58 & 17 \\
\hline 5 & -93 & -67 & 58 & 17 \\
\hline 6 & -92 & -68 & 57 & 17 \\
\hline 7 & -93 & -67 & 58 & 17 \\
\hline 8 & -93 & -68 & 58 & 17 \\
\hline
\end{tabular}

a) Reaction conditions: rac-8a $(12.6 \mathrm{~g}, 1$ eq., $0.2 \mathrm{M}$ in $\mathrm{CH}_{2} \mathrm{Cl}_{2}$ ), $7 \mathbf{b}$ (0.6 eq., $0.2 \mathrm{M}$ in $\mathrm{CH}_{2} \mathrm{Cl}_{2}$ ), $i \mathrm{Pr}_{2} \mathrm{NEt}(0.7$ eq., 0.2 $\mathrm{M}$ in $\left.\mathrm{CH}_{2} \mathrm{Cl}_{2}\right)$, ent-5d $(1.0 \mathrm{~g}, 0.88 \mathrm{mmol}), 0{ }^{\circ} \mathrm{C}, 0.4 \mathrm{~mL} \cdot \mathrm{min}^{-}$ ${ }^{1}$ combined flow, residence time $10 \mathrm{~min}$. ${ }^{\mathrm{b})}$ ee determined by HPLC. ${ }^{\text {c) }}$ Conversion determined by Kagan's equations. d) Selectivity factors calculated from ee data.

Although the hydrolysis of BINOL mono- and diesters and the enantioenrichment of scalemic BINOL (6) by recrystallization are well documented, ${ }^{[19]}$ we wanted to show that both enantiomers of 6 can be easily obtained in highly enantiopure form from either $\mathbf{8 a}$ or $\mathbf{9 a b}$ resulting from the flow process. To this end, representative samples $(500 \mathrm{mg})$ of both compounds, isolated from the effluent of the flow process mediated by $\mathbf{5 d}$ were treated with finely powdered $\mathrm{K}_{2} \mathrm{CO}_{3}$ (4 eq.) in $\mathrm{MeOH}$ for $2 \mathrm{~h}$ at room temperature, and the resulting 6 submitted to enantioenrichment by slow crystallization from toluene (Scheme 4). Through this non-optimized process $(S)-8 \mathbf{a}$ with $96 \%$ ee afforded $(S)-6$ with $99.2 \%$ ee in $75-85 \%$ yield. Starting from the diester $(R)-9$ ab with $67 \%$ ee, $(R)-6$ with $99.6 \%$ ee was obtained in $35-41 \%$ yield.



(S) $-8 \mathbf{a}, 96 \%$ ee<smiles>CC(=O)Oc1ccc2ccccc2c1-c1c(OC(=O)C(C)C)ccc2ccccc12</smiles>

(R)-9ab, $67 \%$ ee

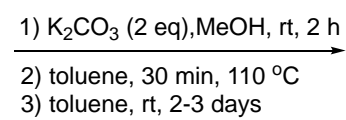

$75-85 \%$ yield

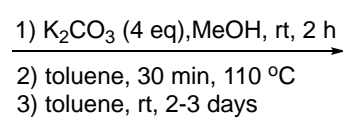

$35-41 \%$ yield

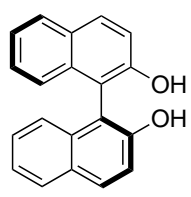

(S) $-6,99.2 \%$ ee

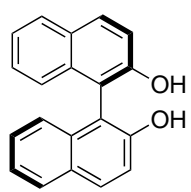

(R)-6, 99.6\% ee
Scheme 4. Recovery of enantiopure BINOL (6) from its mono- and diesters.

\section{Conclusion}

In summary, the polystyrene-immobilized isothiourea $\mathbf{5 d}$ is a suitable catalyst for the acylative KR of O-acetyl BINOL 8a and some of its derivatives with isobutyric anhydride $\mathbf{7 b}$. Working in dichloromethane, the catalyst can used in batch for ten consecutive cycles or in continuous flow for $84 \mathrm{~h}$ without showing any decrease in catalytic activity or in selectivity. With the use of a highly functionalized resin $\left(f=0.88 \mathrm{mmol.} \mathrm{g}^{-1}\right)$, a $58 \%$ conversion is achieved with a residence time of $10 \mathrm{~min}$. in a packed bed reactor containing $1 \mathrm{~g}$. of the functional resin. In this

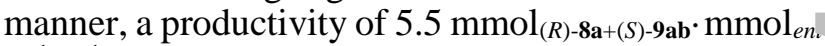
$\mathbf{5 d}^{-1} \cdot \mathrm{h}^{-1}$ can be achieved in a very simple manner. Although some optimization work for the conversioof enantioenriched 8a and 9ab into the enantiomers of BINOL (6) is still required, the present procedure appears as a most promising alternative for the largescale preparation of these industrially important materials.

\section{Experimental Section}

\section{General procedure for the AKR in batch}

To a $5 \mathrm{~mL}$ glass vial at $0{ }^{\circ} \mathrm{C}$ (ice bath), cat. $5 \mathbf{d}(f=0.37$ $\mathrm{mmol} / \mathrm{g}, 135 \mathrm{mg}, 5 \mathrm{~mol} \%$ loading) and $2.5 \mathrm{~mL} \mathrm{CHCl}$, followed by rac-8 $(0.5 \mathrm{mmol}, 1$ eq. $), 7 \mathbf{b}(47.4 \mathrm{mg}, 50 \mu \mathrm{L}$, $0.3 \mathrm{mmol}, 0.6$ eq.) and ${ }^{\mathrm{i}} \mathrm{Pr}_{2} \mathrm{NEt}(45.2 \mathrm{mg}, 61 \mu \mathrm{L}, 0.35 \mathrm{mmol}$, 0.7 eq.), were sequentially added. The reaction mixture was shaken 10 hours. Then, it was filtered and the resin bead were washed with $\mathrm{CHCl}_{3}(3 \times 1 \mathrm{~mL})$. The solvent was concentrated in vacuo and the product was isolated after purification by column chromatography on silica gel with cyclohexane/ethyl acetate $(\mathrm{EtOAc} / c-\mathrm{Hex}=1: 10)$. In the recycling experiments, the functional resin $\mathbf{5 d}$ was used directly in the next reaction cycle. After each cycle, the organic phase was concentrated under vacuum, and the product was isolated after purification by column chromatography as indicated above.

Continuous flow AKR of rac-8a with isobutyric anhydride $7 \mathrm{~b}$ using catalyst $5 d$

Catalyst 5d (1.0 g, $0.37 \mathrm{mmol})$, contained in a sizeadjustable medium pressure glass column (Omnifit glass 
column, $10 \mathrm{~mm} \varnothing$ ) to create a packed bed reactor, was swollen by pumping $\mathrm{CH}_{2} \mathrm{Cl}_{2}$ at $0.1 \mathrm{~mL}$. $\mathrm{min}^{-1}$ for one hour and a cooling jacket was attached to the reactor to maintain an internal temperature of $0^{\circ} \mathrm{C}$. Two syringes mounted on a single syringe pump were used to feed the reagents to the flow reactor,one containing a solution of $\mathbf{8 a}$ and isobutyric anhydride (7b) in dichloromethane, and the second one a solution of DIPEA in dichloromethane, with concentrations adapted to secure the desired ratio $(0.2 \mathrm{M}$ in $\mathbf{8 a}$ in the combined flow). The optimal combined flow rate was initially determined as $0.1 \mathrm{~mL} \cdot \mathrm{min}^{-1}$ at a reaction temperature of $0^{\circ} \mathrm{C}$. Then, the preparative experiment was performed under the optimal condition from $250 \mathrm{~mL}$ of a $0.4 \mathrm{M}$ solution of rac-8a $(32.8 \mathrm{~g}, 100 \mathrm{mmol})$ and $\mathbf{7 b}(10.0$ $\mathrm{mL}, 60 \mathrm{mmol}$ ) in dichloromethane, and $250 \mathrm{~mL}$ of a solution of DIPEA $(11.9 \mathrm{~mL}, 70 \mathrm{mmol})$ in dichloromethane. The experiment took $84 \mathrm{~h}$ to completion, and the measured residence time of the employed setup (visual inspection with a solution of methyl red) was $c a .40 \mathrm{~min}$. Data at different operation times have been summarized in Table S3.5 (see Supporting Information). When the solutions of reagents were consumed, $\mathrm{CH}_{2} \mathrm{Cl}_{2}$ was circulated at $0.1 \mathrm{~mL} \mathrm{~min}^{-1}$ until TLC analysis showed no product in the effluent (ca. $1.5 \mathrm{~h}$ ). The collected outstream was concentrated under reduced pressure and purified by column chromatography on silica gel with cyclohexane/ethyl acetate $(20: 1)$ to yield the corresponding products $(S)-8 \mathbf{a}$ and $(R)-\mathbf{9 a b}$.

\section{Acknowledgements}

Financial support from CERCA Programme/Generalitat de Catalunya, MINECO (CTQ2015-69136-R) and AGAUR/ Generalitat de Catalunya (2017 SGR 1139) is gratefully acknowledged.

\section{References}

[1] For some reviews on the use of BINOL-based, chiral biaryl ligands in asymmetric catalysis, see: a) R. Noyori, H. Takaya, Acc. Chem. Res. 1990, 23, 345; b) W. Tang, X. Zhang, Chem. Rev. 2003, 103, 3029; c) Y. Chen, S. Yekta, A. K. Yudin, Chem. Rev. 2003, 103, 3155; d) Q.H. Xia, H.-Q. Ge, C.-P. Ye, Z.-M. Liu, K.-X. Su, Chem. Rev. 2005, 105, 1603; e) M. Shibasaki, S. Matsunaga, Chem. Soc. Rev. 2006, 35, 269; f) T. Akiyama, J. Itoh, K. Fuchibe, Adv. Synth. Catal. 2006, 348, 999; g) S. J. Connon, Angew. Chem. Int. Ed. 2006, 45, 3909; h) J.-H. Xie, Q.-L. Zhou, Acc. Chem. Res. 2008, 41, 58; i) M. Rueping, A. Kuenkel, I. Atodiresei, Chem. Soc. Rev. 2011, 40, 4539; j) D. Parmar; E. Sugiono; S. Raja; M. Rueping, Chem. Rev. 2014, 114, 9047; k) R. B. Sunoj, Acc. Chem. Res. 2016, 49, 1019.

[2] For some recent examples, see: a) S. Narute, R. Pames, F. D. Toste, D. Pappo, J. Am. Chem. Soc. 2016, 138, 16553; b) H. Y. Kim, S. Takizawa, H. Sasai, K. Oh, Org. Lett. 2017, 19, 3867; c) J.-M. Tian, A.-F. Wang, J.-S. Yang, X.-J. Zhao, Y.-Q. Tu, S.-Y. Zhang, Z.-M. Chen, Angew. Chem. Int. Ed. 2019, 58, 11023.

[3] For the catalytic non-enzymatic KR of biaryl compounds, see: a) H. Aoyama, M. Tokunaga, J. Kiyosu, T. Iwasawa, Y. Obora, Y. Tsuji, J. Am. Chem. Soc. 2005, 127, 10474. For KR with biaryl-derived catalysts, see: b) K. Mori, Y. Ichikawa, M. Kobayashi, Y. Shibata, M. Yamanaka, T. Akiyama, J. Am. Chem. Soc. 2013, 135, 3964; c) S. Shirakawa, X. Wu, K. Maruoka, Angew. Chem. Int. Ed. 2013, 52, 14200; d) D.-J. Cheng, L. Yan, S.-K. Tian, M.Y. Wu, L.-X. Wang, Z.-L. Fan, S.-C. Zheng, X.-Y. Liu,
B. Tan, Angew. Chem. Int. Ed. 2014, 53, 3684; e) S. Arseniyadis, M. Mahesh, P. McDaid, T. Hampel, S. G. Davey, A. C. Spivey, Collect. Czech. Chem. Commun. 2011, 76, 1239.

[4] H. B. Kagan, J. C. Fiaud, Top. Stereochem. 1988, 18, 249

[5] G. Ma, J. Deng, M. P. Sibi, Angew. Chem. Int. Ed. 2014, 53,11818 .

[6] S. Lu, S. B. Poh, Y. Zhao, Angew. Chem. Int. Ed. 2014, $53,11041$.

[7] For recent work on organocatalysed flow processes, see: a) S. Watanabe, N. Nakaya, J. Akai, K. Kanaori, T. Harada, Org. Lett. 2018, 20, 2737; b) J. Lai, S. Sayalero, A. Ferrali, L. Osorio-Planes, F. Bravo, C. Rodríguez Escrich, M. A. Pericàs, Adv Synth Catal. 2018, 360, 2914; c) L. Clot-Almenara, C. Rodriguez-Escrich, M. A. Pericàs, $R S C A d v$. 2018, 8, 6910; d) C. Rodríguez Escrich, M. A. Pericàs, Chem Rec. 2019, 19, 1872; e) A. Ciogli, D. Capitani, N. Di Iorio, S. Crotti, G. Bencivenni, M. Pia Donzello, C. Villani, Eur. J. Org. Chem. 2019 2020; f) M. G. Russell, C. Veryser, J. F. Hunter, R. L. Beingessner, T. F. Jamison, Adv. Synth. Catal. 2019 , https://doi.org/10.1002/adsc.201901185; g) S. B. Ötvös, M. A. Pericàs, C. O. Kappe, Chem. Sci. 2019, 10, 11141

[8] V. B. Birman, X. Li, Org. Lett. 2006, 8, 1351-1354.

[9] J. Merad, P. Borkar, T. Bouyon Yenda, C. Roux, J.-M. Pons, J.-L. Parrain, O. Chuzel, C. Bressy, Org. Lett. 2015, 17, 2118.

[10] X. Yang, V. B. Birman, Adv. Synth. Catal. 2009, 351, 2301.

[11] S. Qu, M. D. Greenhalgh, A. D. Smith, Chem. Eur. J. 2019, 25, 2816.

[12] E. Vedejs, M. Jure, Angew. Chem. Int. Ed. 2005, 44, 3974.

[13] a) V. B. Birman, L. Guo, Org. Lett. 2006, 8, 4859; b) V. B. Birman, H. Jiang, X. Li, L. Guo, E. W. Uffman, J. Am. Chem. Soc. 2006, 128, 6536; c) V. B. Birman, H. Jiang, X. Li, Org. Lett. 2007, 9, 3237.

[14] J. Izquierdo, M. A. Pericàs. ACS Catal. 2016, 6, 348.

[15] a) S. Wang, J. Izquierdo, C. Rodríguez-Escrich, M. A. Pericàs, ACS Catal. 2017, 7, 2780; b) S. Wang, C. Rodríguez-Escrich, M. A. Pericàs, Angew. Chem. Int. Ed. 2017, 56, 15068.

[16] a) R. M. Neyyappadath, R. Chisholm, M. L Greenhalgh, C. Rodríguez-Escrich, M. A. Pericàs, G. Hähner, A.D. Smith, ACS Catal. 2018, 8, 1067; b) N. Ranjan Guha, R. M. Neyyappadath, M. D. Greenhalgh, R. Chisholm, S. M. Smith, M. L. McEvoy, C. M. Young, C. Rodríguez-Escrich, M. A. Pericàs, G. Hähner, A. D. Smith, Green Chem. 2018, 20, 4537.

[17] a) X. Li, H. Jiang, E. X. Uffman, L. Guo, Y. Zhang, X. Yang, V. B. Birman, J. Org. Chem. 2012, 77, 1722; b) J. Merad, J.-M. Pons, O. Chuzel, C. Bressy, Eur. J. Org. Chem. 2016, 5589. 
[18] A. Vidal-Ferran, N. Bampos, A. Moyano, M. A. Pericàs, A. Riera, J. K. M. Sanders, J. Org. Chem. 1998, 63, 6309 .
[19] a) N. Aoyagi, N. Ogawa, T. Izumi, Tetrahedron Lett. 2006, 47, 4797; b) M. Juárez-Hernandez, D. V. Johnson, H. L. Holland, J. McNulty, A. Capretta, Tetrahedron: Asymmetry 2003, 14, 289. 


\section{UPDATE}

Continuous Flow Preparation of Enantiomerically Pure BINOL(s) by Acylative Kinetic Resolution

Adv. Synth. Catal. Year, Volume, Page - Page

Junshan Lai, Rifahath M. Neyyappadath, Andrew D. Smith and Miquel A. Pericàs*

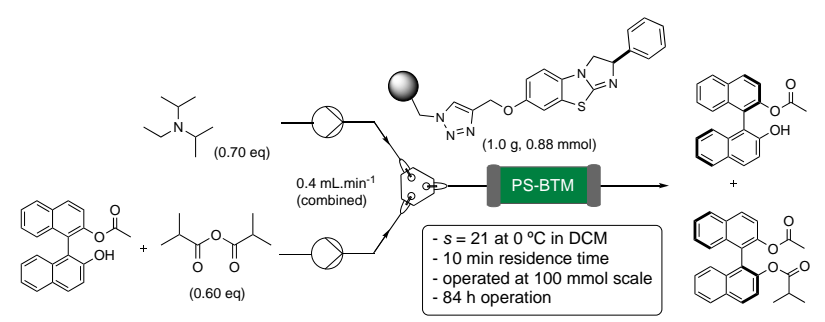

